\title{
Grouping promotes risk-taking in unfamiliar settings
}

Kareklas, Kyriacos; Elwood, Robert W.; Holland, Richard A.

\section{Behavioural Processes}

DOI:

10.1016/j.beproc.2018.01.003

Published: 01/03/2018

Peer reviewed version

Cyswllt i'r cyhoeddiad / Link to publication

Dyfyniad o'r fersiwn a gyhoeddwyd / Citation for published version (APA):

Kareklas, K., Elwood, R. W., \& Holland, R. A. (2018). Grouping promotes risk-taking in unfamiliar settings. Behavioural Processes, 148, 41-45. https://doi.org/10.1016/j.beproc.2018.01.003

\footnotetext{
Hawliau Cyffredinol / General rights

Copyright and moral rights for the publications made accessible in the public portal are retained by the authors and/or other copyright owners and it is a condition of accessing publications that users recognise and abide by the legal requirements associated with these rights.

- Users may download and print one copy of any publication from the public portal for the purpose of private study or research.

- You may not further distribute the material or use it for any profit-making activity or commercial gain

- You may freely distribute the URL identifying the publication in the public portal ?
}

Take down policy

If you believe that this document breaches copyright please contact us providing details, and we will remove access to the work immediately and investigate your claim. 
5

6

7

8 Lisburn Road, BT9 7BL, UK

$9 \quad{ }^{2}$ School of Biological Sciences, Bangor University, Deiniol Road, Bangor, Gwynedd, LL57

10

11

12

13

14

15

16

17

18

19

20

21

22

23

24

25

26

\section{Grouping promotes risk-taking in unfamiliar settings}

Kyriacos Kareklas ${ }^{1 *}$

Robert W. Elwood ${ }^{1}$ and

Richard A. Holland ${ }^{2}$

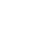

Affiliations:

${ }^{1}$ School of Biological Sciences, Queen's University Belfast, Medical Biology Centre, 97

2UW, UK

11

*Correspondence: kkareklas01@ qub.ac.uk

3

4

5

16

17

18

19

21

22 


\section{ABSTRACT}

Acting collectively in a group provides risk-reducing benefits. Yet individuals differ in how they take risks, with some being more willing than others to approach dangerous or unfamiliar settings. Therefore, individuals may need to adjust their behaviour when in groups, either as a result of perceiving greater safety or to coordinate collective responses, the latter of which may rely on within-group dynamics biased by group composition. In zebrafish we explored how these aspects of grouping affect risk-taking behaviour by comparing solitary to group conditions and testing the ability of group-member solitary responses to predict collective responses. We focused on approach-latency towards a novel object and an unusual food to test this, for shoals of five fish. There was no indication that collective latencies are predicted by how each fish responded when alone in terms of the extremes, the variance or the mean of group-member latency towards the unusual food and the novelobject. However, fish were overall faster and less variable in their approach when shoaling. This indicates lower risk aversion by individuals in groups, presumably as a result of group safety. An interesting consequence of the overall low risk-aversion in shoals is that more riskaversive fish adjust their behaviour more than less risk averse fish.

KEYWORDS: social facilitation; risk-taking; zebrafish; shoal; collective behaviour 46 


\section{INTRODUCTION}

The benefits of being organised in groups have long been noted in many species (Scott, 1956). Threat detection and anti-predator functions are the most important examples, both of which depend on cooperation and synchronisation (Pitcher and Parrish, 1986). If information is successfully and rapidly distributed between group members then each member may spend less time on predator vigilance and more on feeding, while also improving efficiency when exploring areas for food (Magurran and Pitcher, 1983; Pitcher and Parrish, 1986; Laland and Williams, 1997). Further, the probability of an individual being attacked diminishes as group size increases because of dilution (Foster and Treherne, 1981) and the predator is less able to choose a specific target (Jeschke and Tollrian, 2007). Although these benefits should promote group formation, the tendency to group varies with local conditions (Magurran and Pitcher, 1983; Pitcher and Parrish, 1986). For example, killifish Fundulus diaphanus minimize competition by being individually spaced when sensing food odours and minimise risk by forming large aggregates when alarmed by cues from a dead conspecific. In more complex environments where both food and alarm cues are present, they average their response by forming smaller groups (Hoare et al., 2004). Therefore, group formation may depend on what is beneficial to individuals in each set of conditions.

Individuals of a range of species, however, exhibit consistent marked differences in their behavioural tendencies, including their willingness to take or avoid risk in unfamiliar or dangerous situations (Coleman and Wilson, 1998; Toms et al., 2010; Wolf and Weissing, 2012). Individual differences in risk-taking suggest different strategies: those taking less risk typically benefit from reduced mortality, whereas those taking more risk may benefit from more rewards and increased growth (Stamps, 2007). If individuals retain at least some aspects of their own risk-taking tendencies when they are in groups then group cohesion and unified responses may be disrupted (Ward et al., 2004; Webster et al., 2007; Magnhagen and 
Bunnefeld, 2009). Therefore, for the group to function, individuals should, at least partially, adjust their behavioural tendencies (Pitcher and Parish, 1986; Jeschke and Tollrian, 2007; Miler and Gerlai, 2012; McDonald et al., 2016).

The benefits offered by organising into groups suggest that, in identical situations, being alone is more risky than being in a group (Magurran and Pitcher, 1983; Webster and Ward, 2011; Ward, 2012). Therefore, being in a group may facilitate less risk-aversive behaviour in all individuals. For example, individual fish become faster to approach food, more active and more explorative when in a group than when alone (Webster et al., 2007; Ward, 2012). This social facilitation of an increase in risk-taking behaviour is often attributed to the simple presence of others, and is arguably the result of the perceived safety offered by being organised in groups (Ryer and Olla, 1992; Guerin, 2010; Ward, 2012). Social facilitation of behavioural changes can be exhibited in both smaller and bigger groups, but the extent of the effect typically increases with group size (Ward et al., 2011; Ward, 2012) and may vary with individual tendencies, e.g. in risk-taking (Jolles et al., 2014).

Alternatively, changes to individual behaviour may simply be associated with the maintenance of group cohesion when responding collectively (Couzin and Krause, 2003). The collective responses of a group may arise from mechanisms of conformity, where individuals will progressively conform to the response of the majority or follow nearneighbours (Webster and Ward, 2011). However, majority responses may involve decisions made between individuals (Conradt and Roper, 2005; Sumpter et al., 2008; Couzin et al., 2011), which can be influenced by the nature of the individual differences between the animals comprising the group (Webster and Ward, 2011; Ioannou and Dall, 2016). On one hand, collective responses may reflect the mean behavioural tendency of individuals, but may also be limited by the extent to which differences between individuals affect the maintenance of group cohesion. For example, groups composed of bold fish are faster to approach food than if composed of shy fish (Dyer et al., 2009) and individual differences in feeding 
motivation can drive differences in grouping tendency, with hungrier fish being less likely to keep close to group mates (Webster et al., 2004). On the other hand, the majority may choose to follow a leader, such as a more reward-motivated or less risk-aversive individual (Krause et al., 1992; Krause et al., 2000; Ward et al., 2004). Consequently, collective (cohesive) responses would be largely determined by the behavioural response of leaders and the ability of followers to maintain short delays (Ioannou and Dall, 2016). Leadership can arise in larger and smaller groups (Couzin et al., 2005; Johnstone and Manica, 2011), but majority-decisions are generally facilitated in larger groups (Sumpter et al., 2008; Ward et al., 2008).

Fish groups are traditionally referred to as schools or shoals, with discriminations between the two relying on aspects of sociability and function; shoaling may refer generally to fish groups or those formed for social reasons, conversely schooling specifically refers to directed movement (Pitcher and Parrish, 1986). However, as Delcourt and Poncin (2012) point out, groups can be better characterised by precise metrics such as polarity (i.e. the level in which fish orient towards the same direction) and cohesion (i.e. the level in which fish stay close together). In zebrafish, larger shoals are less polarised and this could, arguably, be linked to the risk-reduction offered by more individuals staying together (Miller and Gerlai, 2012). However, cohesion and polarisation generally fluctuate, which may affect information transfer during zebrafish collective responses (Miller and Gerlai, 2011). To elucidate what drives collective response in zebrafish shoals, we first examine effects of social facilitation by comparing shoaling and solitary risk-taking in Danio rerio. We then examine the ability of shoal-member solitary response in predicting collective response, as a process of intermember interactions. We aimed to identify any changes in behaviour due to social conditions and whether the solitary behaviour of shoal members determines their collective response.

The approach latency of individuals and shoals was used to indicate levels of risktaking in two contexts, novel-object exploration and feeding on unusual food (Toms et al., 2010). First, we compared the individual response in a solitary condition (slowest solitary 
131 fish) to the individual response during shoaling (slowest shoal member). Based on the

132 literature, we expected greater risk-taking by fish during shoaling, as compared to being 133 alone (Webster et al., 2007; Ward, 2012). Second, the predictive power of shoal-member solitary behaviour was tested by examining whether collective latencies (i.e. until last fish, given cohesion was maintained) were: slower for shoals with members that have on average slower solitary responses (effect of general composition; Dyer et al., 2009), slower for shoals with members more dissimilar in their solitary response (degree of conformity; Ward et al., 2004), faster for shoals whose fastest member was particularly fast when alone (leadership by most reward-driven; Krause et al., 1992) and slower for shoals whose slowest member was particularly slow when alone (delay by most risk-aversive; Ioannou and Dall, 2016). 12h dark (07.00-19.00) and food was provided daily (TetraMin® tropical flakes).

\section{METHODS}

\subsection{Animals and husbandry}

Male D. rerio zebrafish were acquired from a local supplier and first kept individually $(\mathrm{n}=50)$ in $15 \mathrm{~L}$ tanks $(30 \mathrm{~cm} \times 25 \mathrm{~cm} \times 20 \mathrm{~cm})$ and then as shoals of five $(\mathrm{n}=10)$ in $25 \mathrm{~L}$ tanks $(42 \mathrm{~cm} \times 30 \mathrm{~cm} \times 20 \mathrm{~cm})$. Given strain variations in the supplier's stock were unknown, we used only males that show no strain preferences during shoaling (Snekser et al., 2010), which also removed the chance of mating during group-living and controlled for sex-related differences in risk-taking. The different tank sizes used gave reasonable space for the individuals and shoals. During individual housing, neighbouring tanks on either side (two individuals) were kept visible to control effects from social isolation. Housing tanks were enriched with shelter (plastic pipes), plants and soft sediment. The water in the tanks was filtered, regularly tested, kept at $25 \pm 1^{\mathrm{O}} \mathrm{C}$ and maintained between 6.8-7.6pH. Photoperiods were kept at $12 \mathrm{~h}$ light and

\subsection{Behavioural tests}


Fish were left to acclimatise to individual housing for a week and then tested

157 individually in their solitary housing tanks. A week following individual (solitary) testing, all

158 fish were randomly arranged in sets of five and housed together for a further week. This provided time for individuals to experience group living before being tested for their collective response as a shoal, carried out in the housing tanks of shoals. Both individual and shoal testing was repeated in two contexts: when exploring/inspecting a novel object and when feeding on unusual food-items (not previously offered to them in the laboratory). When tested individually, fish were given brine shrimp at the feeding test and 48 hours later presented with a $\sim 10 \mathrm{~cm}$ long plastic soldier figurine for the novel-object test. When tested in shoals, fish were given bloodworm at the feeding test and 48 hours later presented with a $\sim 12 \mathrm{~cm}$ long plastic dinosaur toy for the novel-object test. The location and time (11.0012.00) items were presented were kept constant, but a change in food and objects maintained novelty and controlled for episodic-like memorisation of familiar items (Hamilton et al., 2016). Objects were lowered at an uncovered part of the tank by a pulley system to the bottom of the tank, at which point recording started. Food was released with a pipette from the top-edge of the front-facing tank-wall and recording started after release in the water. The experimenter remained hidden behind opaque sheets surrounding the tanks during tests. Individuals and shoals were given 300s to approach the object or food and if no approach was noted within this period, latency was recorded as 300s. Latency to approach the food was measured until starting to feed and latency to approach the novel object was measured until fish were within a distance of $\sim 1.5$ body lengths from the object, estimated through a digital grid from recordings (Kinovea $\odot$ version 8; J. Charmant \& Co.). In keeping with other studies (Magnhagen and Bunnefeld, 2009; McDonald et al., 2016), all fish had the same order of testing, both for social-conditions and context. Further, all shoals received the same items in either social condition. The order of testing and of previously experiencing particular items could have effects on latency. Importantly, however, it ensures that any carry-over effects 
182

from experience of previous items and from temporal order would be identical for all fish and therefore not contribute to inter-individual and inter-shoal variance (Wilson et al., 2012).

In order to validate responses as being collective we examined cohesion (ability to stay together) by identifying dispersal events and significant reductions in estimations of nearest-neighbour distances from video recordings of the tests. No dispersal events were observed during any of the shoal tests (i.e. no fish stayed behind or changed direction; Croft et al., 2003) and the distance from closest neighbours did not exceed average body-length $(<5 \mathrm{~cm})$ as extrapolated from observing test-recordings through a digital grid (Kinovea@).The response of all shoals was fast (3-22 seconds), synchronous, in that individuals responded together, but not polarised (i.e. most individuals were not oriented towards the same direction). This made it difficult to record accurate times for all fish and calculate other indicators of cohesion, such as delays between initiator and follower response (Krause et al., 2000; Ioannou and Dall, 2016).We therefore recorded approach by the last fish to indicate collective latency times, i.e. time needed for the whole shoal to approach together. Note that although fish in the shoal were not individually marked, the use of the slowest fish as the collective measure is a conservative approach because all other fish were faster.

\subsection{Calculations and Analysis}

Calculations and statistical tests were carried out in Minitab ${ }^{\circledR}$ statistical software (version 17; Minitab Inc., State College, PA). Latencies of individuals from the solitary tests were compared ( $t$-test) and correlated (Pearson's $r$ ) between feeding and novel-object to examine consistency and order effects. To examine changes with social conditions (solitary or shoaling) we carried out discrete comparisons between the solitary latency time of the slowest fish from each set of five and the slowest fish when acting as a shoal, for both the novel-object exploration and the feeding context. We cannot guarantee that the slowest in each social condition was the same fish, but the slowest fish in the solitary condition was at most as latent as the slowest in the group condition. Thus, providing a conservative method to 
208

209

210

211

212

213

214

216

217

218

219

220

221

222

223

224

225

226

227

228

229

230

231

232

233

assess change between the social conditions. For discrete comparisons we used Welch's $t$-test for mean changes (does not assume equal variances), Cohen's $d$ for effect size and Levene's $W$ for equal variances. Then, using a linear mixed model (LMM), we tested if collective latencies differed between contexts and sets of fish (random factor to avoid pseudoreplication), and predicted by the mean (slower members promote slower collective response), standard deviation (more variable shoals are slower to collectively respond), minimum (leadership by a faster leader) or maximum (delay by a slower follower) of the solitary responses of group members.

\section{RESULTS}

The latencies of individuals when tested alone were strongly positively correlated between contexts (Pearson's; $r=0844, P<0.001$ ), confirming that individual behaviour in either context is linked to consistent individual tendency and not a random effect. Mean latency did not differ between tests in either social condition $(P>0.5)$, indicating no order or context effects. Latencies of solitary individuals in the two contexts were varied and ranged between $1 \mathrm{~s}$ and $300 \mathrm{~s}$, but collective latencies in the two contexts were relatively uniform between shoals, ranging between 3 s to 22 s (supplementary material). The slowest individuals from each set of five, when tested as solitary individuals, were significantly slower and more variable in their response than the response of the slowest group member when shoaling (Figure 1), both during novel-object exploration (Welch's $t_{10}=-3.91, P=0.004$; Levene's $\left.W_{1,20}=7.78, \quad P=0.012 ; \quad d=1.749\right)$ and feeding (Welch's $t_{10}=-2.81, \quad P=0.020 ; \quad$ Levene's $\left.W_{1,20}=6.04, P=0.024 ; d=1.257\right)$. The overall decrease in latency when shoaling, as well as the low variance between shoals, indicated that differences in response between solitary and shoaling conditions were greater for individuals that were the most latent during the solitary tests (Figure 1). The solitary latency of shoal members had no effect, with the mean, variance, maximum and minimum failing to predict collective latency (LMM; $P>0.5$, 
$\left.234 R^{2}<0.02\right)$. In particular, sets of fish with lower mean solitary latency did not have lower

235 collective latencies when shoaling, sets of fish with greater variability in solitary responses

236 did not have slower shoaling responses and neither the slowest solitary latency of each set

237 (follower delay) or the fastest solitary latency of each set (leader initiation) predicted

238 collective latencies when shoaling .

\section{DISCUSSION}

This study demonstrates the effects of being in a small group compared to being alone in different contexts. It revealed that fish were faster on average when tested as a group than individually, both during feeding and novel-object exploration. This was shown when the slowest solitary individuals were compared with the slowest in the shoal (Figure 1) and hence slower than all fish responding collectively as a shoal. Particularly slow solitary fish were the ones differing most from the collective response and hence the ones changing most between social conditions (Figure 1). This indicates that collective behaviour is skewed towards lower risk-aversion and, as a result, the most risk-aversive individuals change the most. However, collective responses by shoals were not predicted by between-shoal differences in the solitary behavioural tendency of their members. This suggests that increases in risk-taking when shoaling and the ability to maintain fast collective responses is more likely a result of the effects of social conditions on individual behaviour, and not due to the individual tendencies of members affecting collective response. Although, the low predictive power of shoalmember solitary-tendency may also be due to the single collective latency measure not reflecting subtle inter-group dynamics.

Studies on fish show how collective responses can be driven by agreement between the members of a group (Sumpter et al., 2008; Couzin et al., 2011). Collective responses were confirmed for all shoals in the present study by the observed synchrony and the lack of instances where members of the group stayed behind or changed direction (Croft et al., 
2003). However, the mean and variance in the individual response of members did not predict the collective response, which suggests that the degree of similarity in the solitary tendency between members of a group does not affect how they act collectively during shoaling contexts. This may be due the small size of our shoals, where collective decisions may be infrequent, relying on quorum processes (Ward et al., 2008), and individual-differences may be greater, reducing agreement (Magurran and Pitcher, 1983; Herbert-Read et al., 2013).

An alternative explanation may be that some individuals take leading positions and others follow (Krause et al., 2000). Leadership can change dynamically and it has been linked to both individual risk-taking behaviour and reward motivation (Krause et al., 1992; Ioannou and Dall, 2016). Risk-taking individuals are typical contenders for leadership, such as in stickleback and mosquitofish (Ward et al., 2004; Burns et al., 2012), in that the other members of the group follow the highest risk-taking fish. Further, leadership during feeding may go to the hungriest fish, such as in the common roach (Krause et al., 1992). However, there was no indication that shoals whose fastest member was faster to feed and explore in solitary testing were faster during group testing. Hierarchical processes can also be evident via follower behaviour (Krause et al., 2000; Couzin et al., 2005; Ioannou and Dall, 2016). Although risk-aversive individuals that are more reluctant to follow would be more likely to stay behind and reduce cohesion (Ward et al., 2004; Johnstone and Manica, 2011), a delay by individuals with the slowest solitary response was not indicated, with the slowest solitarylatency not predicting collective latency during group testing. We consider that this could be a limitation of being unable to track subtle interactions within shoals. Indeed, effects by individual risk-taking tendency on leader-follower interactions have been demonstrated for small groups in other fish, e.g. in pairs of three-spined sticklebacks Gasterosteus aculeatus (Jolles et al., 2014; Ioannou and Dall, 2016), and related to social feedback (Harcourt et al., 2009). Collective decisions that suppress individual-tendencies are preferred to hierarchies only in bigger groups of three-spined sticklebacks, e.g. 10-memeber shoals (McDonald et al., 
2016). But the most limiting factor to detecting leadership or agreement effects in our study, is that all shoals responded collectively and with limited differences between them. Indeed, the low variability in response between shoals in both contexts suggests that the changes exhibited by being in a group are consistently independent of differences between shoals in group composition.

Fish species with lower grouping tendencies have previously been shown to exhibit more inter-individual differences in risk-taking and foraging behaviour than fish with higher grouping tendencies (Magurran and Pitcher, 1983). Although, from our results it seems that even in species with significant shoaling tendencies, such as the one studied here (Miller and Gerlai, 2011; Suriyampola et al., 2016), individual behaviour depends on social conditions, whether solitary or shoaling. When fish are on their own, the inability to have both safety and resource abundance is resolved by phenotypic variability between individuals (Stamps et al., 2011). This is likely to optimise survival based on individual states, such as morphology (e.g. size) and physiology (e.g. stress hormone levels) (Wolf and Weissing, 2012). However, individual behaviour is adjusted during shoaling (Webster et al., 2007; Ward, 2012). These adjustments might rely on simple rules, such as individuals remaining close to others in order to optimise pay-offs (Ryer and Olla, 1991). The perceived benefits of group functions (e.g. increased growth and reduced mortality) also influence how individuals adjust behaviour, i.e. the reduced risk offered when in a group may facilitate shorter approach latencies in all group members (Ward, 2012). Effects of social facilitation on risk-taking, similar to the ones shown here, have also been shown in other fish, such as the three-spined stickleback and the mosquitofish (Ward et al., 2004; Webster et al., 2007; Ward et al., 2012). The facilitation of risk-taking and general faster approach could be attributed to the benefits of shoaling as in these other fish species, but also due to the reduction of stress-levels from being first housed individually and then in groups, something particularly relevant to zebrafish phenotypic expression (Kalueff et al., 2014). The consistently low variability in collective response 
312

313

between shoals (Figure 1) and the inability of differences in composition predicting collective response, emphasise further the likelihood that the collective latencies recorded in our study are those of social facilitation. The pay-offs offered by a collective responses may suffice in driving individuals to stick together, while the perception of safety-in-numbers and the reduction of stress drives individuals in a group to be less aversive to risk.

Notably, since shoaling decreases risk-aversion to uniform levels, the most riskaversive fish show the greatest behavioural change (Figure 1), a likely a result of shoaling being perceived as a lower-risk condition by all group members. Individuals often exhibit such differences in flexibility when encountering changes in perceived levels of risk, e.g. between high and low predation-risk levels (Quinn and Cresswell, 2005; Briffa, 2013; Kareklas et al., 2016). While flexibility is energetically costly (Dall et al., 2004), the maintenance of high levels of risk-taking can also be maladaptive when risks are extremely high (Johnson and Sih, 2005; Kareklas et al., 2016). These costs are resolved by variable levels of flexibility within a population and may be linked to life-history trade-offs, e.g. in growth/mortality or reproductive success (Wolf et al., 2008; Stamps, 2011). Comparisons across social conditions in other fish species show similar individual effects. For example, shoaling in perch also reduced risk-avoidance and variance between individuals, and it was also the most latent solitary fish that changed the most when in a group (Magnhagen and Bunnefeld, 2009). In a recent study on zebrafish pairs, individual differences in flexibility across social conditions were found to be consistent and linked to the exploratory tendency of partners (Guayasamin et al., 2017). The mechanisms mediating the dramatic shift between individual variability and group cohesion require further investigation. The current evidence argues for the need to understand better the effect of social conditions in facilitating collective responses and to examine the phenotypic transitions exhibited by individuals with changes in social conditions. This is particularly relevant for species like zebrafish that 
337 exhibit dynamic changes in their level of social organisation depending on external factors 338 (Suriyampola et al., 2016).

ACKNOWLEDGEMENTS:

342 We would like to thank Gillian Riddell, Claire McAroe and Sascha Cox for technical 343 assistance.

\section{ETHICAL APPROVAL:}

All applicable guidelines for the care and use of animals were followed (ASAB/ABS, 2016) and fish numbers were kept to the minimum required. Following inspection, the DHSSPS Northern Ireland deemed no need for licensing. Fish were kept for separate tests.

\section{DATA ACCESSIBILITY :}

Raw data were submitted as supplementary material with this article.

FUNDING:

354 The project and K.K. were funded by the Department for Employment and Learning, 355 Northern Ireland.

\section{COMPETING INTERESTS:}

The authors have no competing interests. 
363

364

365

366

367

368

369

370

371

372

373

374

375

376

377

378

379

380

381

382

383

384

385

386

387

388

389

390

391

392

393

\section{REFERENCES:}

ASAB/ABS. (2016). Guidelines for the treatment of animals in behavioural research and teaching. Animal Behaviour, 111, I-IX .

Briffa, M., 2013. Plastic proteans: reduced predictability in the face of predation risk in hermit crabs. Biol. Lett. 9, 20130592 (doi:10.1098/rsbl.2013.0592)

Burns, A.L, Herbert-Read, J.E., Morrell, L.J., Ward, A., 2012. Consistency of leadership in shoals of mosquitofish (Gambusia holbrooki) in novel and in familiar environments. PLoS One 7, e36567 (doi: 10.1371/journal.pone.0036567).

Coleman, K., Wilson, D.S., 1998. Shyness and boldness in pumpkinseed sunfish: individual differences are context-specific. Anim. Behav. 56, 927-936

Conradt, L., Roper, T. J. 2005. Consensus decision making in animals. Trends Ecol. Evol. 20, 449-456.

Couzin, I.D., Ioannou, C.C., Demirel, G., Gross, T., Torney, C.J., Hartnett, A., Conradt, L., Levin, S.A. and Leonard, N.E., 2011. Uninformed individuals promote democratic consensus in animal groups. Science $334,1578-1580$.

Couzin, I.D., Krause, J., 2003. Self-organization and collective behavior in vertebrates. Adv. Stud. Behav. 32, 175.

Couzin, I.D., Krause, J., Franks, N.R., Levin, S.A., 2005. Effective leadership and decision-making in animal groups on the move. Nature 433, 513-516.

Croft, D.P., Arrowsmith, B.J., Bielby, J., Skinner, K., White, E., Couzin, I.D., Magurran, A.E., Ramnarine, I. and Krause, J., 2003. Mechanisms underlying shoal composition in the Trinidadian guppy, Poecilia reticulata. Oikos 100, 429-438.

Dall, S.R, Houston, A.I., McNamara, J.M., 2004.The behavioural ecology of personality: consistent individual differences from an adaptive perspective. Ecol. Lett. 7, 734-739

Delcourt, J., \& Poncin, P., 2012. Shoals and schools: back to the heuristic definitions and quantitative references. Rev. Fish Biol. Fish. 22, 595-619.

Dyer, J.R, Croft, D.P., Morrell, L.J., Krause, J., 2009. Shoal composition determines foraging success in the guppy. Behav. Eco. 20, 165-171.

Foster, W. A., Treherne, J. E., 1981. Evidence for the dilution effect in the selfish herd from fish predation on a marine insect. Nature, 293, 466-467.

Guayasamin, O. L., Couzin, I. D., \& Miller, N. Y. (2017). Behavioural plasticity across social contexts is regulated by the directionality of inter-individual differences. Behav. Proc., 141, 196-204. 
394

395

396

397

398

399

400

401

402

403

404

405

406

407

408

409

410

411

412

413

414

415

416

417

418

419

420

421

422

423

Guerin, B., 2009. Social facilitation. Campridge University Press, Cambridge

Hall, D., Suboski, M.D., 1995. Visual and olfactory stimuli in learned release of alarm reactions by zebra danio fish (Brachydanio rerio). Neurobiol. Learn.Mem. 63, 229-240.

Hamilton, T.J., Myggland, A., Duperreault, E., May, Z., Gallup, J., Powell, R.A., Schalomon, M., Digweed, S.M., 2016. Episodic-like memory in zebrafish. Animal cognition, 19(6), pp.1071-1079.

Harcourt, J. L., Ang, T. Z., Sweetman, G., Johnstone, R. A., Manica, A., 2009. Social feedback and the emergence of leaders and followers. Curr.Biol., 19, 248-252.

Herbert-Read, J. E., Krause, S., Morrell, L. J., Schaerf, T. M., Krause, J., \& Ward, A. J. W., 2013. The role of individuality in collective group movement. Proc. R. Soc. B 280, 20122564.

Hoare, D.J., Couzin, I.D., Godin, J.G., Krause, J. 2004. Context-dependent group size choice in fish. Anim. Behav. 67, 155-164.

Ioannou, C. C., \& Dall, S. R., 2016. Individuals that are consistent in risk-taking benefit during collective foraging. Sci. Rrep. 6, 33991 (doi: 10.1038/srep33991)

Jeschke, J.M., Tollrian, R., 2007. Prey swarming: which predators become confused and why?. Anim. Behav., $74,387-393$

Johnson, J.C., Sih, A., 2005. Precopulatory sexual cannibalism in fishing spiders (Dolomedes triton): a role for behavioral syndromes. Behav. Ecol. Sociobiol. 58, 390-396.

Johnstone, R.A., Manica, A., 2011. Evolution of personality differences in leadership. Proc. Natl. Acad. Sci. USA $108,8373-8378$.

Jolles, J. W., Fleetwood-Wilson, A., Nakayama, S., Stumpe, M. C., Johnstone, R. A., \& Manica, A., 2014. The role of previous social experience on risk-taking and leadership in three-spined sticklebacks. Behav. Ecol., 25, 1395-1401.

Kalueff, A. V., Stewart, A. M., \& Gerlai, R., 2014. Zebrafish as an emerging model for studying complex brain disorders. Trends Pharmacol. Sci., 35, 63-75.

Kareklas, K., Arnott, G., Elwood, R.W., Holland, R.A., 2016, Plasticity varies with boldness in a weaklyelectric fish. Front. Zool. 13 (doi: 10.1186/s12983-016-0154-0)

Kareklas, K., Elwood, R.W. \& Holland, R.A., 2017. Personality effects on spatial learning: comparisons between visual conditions in a weakly-electric fish. Ethology (doi: 10.1111/eth.12629)

Krause, J., Bumann, D., Todt, D., 1992. Relationship between the position preference and nutritional state of individuals in schools of juvenile roach (Rutilus rutilus). Behav. Ecol. Sociobiol., 30, 177-180. 
424

425

426

427

428

429

430

431

432

433

434

435

436

437

438

439

440

441

442

443

444

445

446

447

448

449

450

451

452

453

Krause, J., Hoare, D., Krause, S., Hemelrijk, C.K., Rubenstein, D.I., 2000. Leadership in fish shoals. Fish Fish. 1, 82-89.

Laland, K.N. \& Williams, K., 1997. Shoaling generates social learning of foraging information in guppies. Anim. Behav. 53, 1161-1169

Magnhagen, C. \& Bunnefeld, N., 2009. Express your personality or go along with the group: what determines the behaviour of shoaling perch?. Proc. R. Soc. B 276, 3369-3375

Magurran, A.E, Pitcher, T.J., 1983. Foraging, timidity and shoal size in minnows and goldfish. Behav. Ecol. Sociobiol. $12,147-152$

McDonald, N.D, Rands, S.A., Hill, F., Elder, C., Ioannou, C. C., 2016. Consensus and experience trump leadership, suppressing individual personality during social foraging. Sci. Adv. 2, e1600892 (doi:10.1126/sciadv.1600892)

Miller, N.Y, Gerlai, R., 2011. Shoaling in zebrafish: what we don't know. Rev. Neuroscience. 22, 17-25

Miller, N.Y, Gerlai, R.,2012. From schooling to shoaling: patterns of collective motion in zebrafish (Danio rerio). PLoS One, 7, e48865. (doi: 10.1371/journal.pone.0048865)

Pitcher, T.J., Parrish, J.K., 1993. Functions of shoaling behaviour in teleosts, in: Pitcher, T.J (Ed.), Behaviour of teleost fishes. Chapman and Hall, London , pp. 363-439.

Quinn, J. L., Cresswell, W., 2005. Personality, anti-predation behaviour and behavioural plasticity in the chaffinch Fringilla coelebs. Behaviour 142,1377-1402

Ryer, C.H., Olla, B.L., 1991. Information transfer and the facilitation and inhibition of feeding in a schooling fish. Environ. Biol. Fish. 30, 317-323.

Scott, J.P., 1956. The analysis of social organization in animals. Ecology 37, 213-221.

Snekser, J. L., Ruhl, N., Bauer, K., \& McRobert, S. P., 2010. The influence of sex and phenotype on shoaling decisions in zebrafish. Int. J. of Comp. Psychol. 23, 70-81.

Stamps, J.A., 2007. Growth-mortality tradeoffs and 'personality traits' in animals. Ecol. Lett. 10, 355-363

Sumpter, D.J., Krause, J., James, R., Couzin, I.D., Ward, A.J., 2008. Consensus decision making by fish. Curr. Biol. 18, 1773-1777.

Suriyampola, P.S., Shelton, D.S., Shukla, R., Roy, T., Bhat, A., Martins, E.P., 2016. Zebrafish social behavior in the wild. Zebrafish, 13, 1-8.

Toms, C.N., Echevarria, D. . \& Jouandot, D.J., 2010. A methodological review of personality-related studies in fish: focus on the shy-bold axis of behavior. Int J. Comp. Psychol. 23, 1-25. 
454

455

456

457

458

459

460

461

462

463

464

465

466

467

468

469

470

471

472

473

474

475

476

477

478

479

480

481

482

Ward, A. J., 2012. Social facilitation of exploration in mosquitofish (Gambusia holbrooki). Behav. Ecol. Sociobiol. 66, 223-230.

Ward, A.J., Herbert-Read, J.E., Sumpter, D.J., Krause, J., 2011. Fast and accurate decisions through collective vigilance in fish shoals. Proc. Natl. Acad. Sci. USA 108, 2312-2315.

Ward, A.J., Sumpter, D.J., Couzin, I.D., Hart, P.J., \& Krause, J., 2008. Quorum decision-making facilitates information transfer in fish shoals. Proc. Natl. Acad. Sci. USA 105, 6948-6953.

Ward, A.J., Thomas, P., Hart, P.J., Krause, J., 2004. Correlates of boldness in three-spined sticklebacks (Gasterosteus aculeatus). Behav. Ecol. Sociobiol. 55, 561-568

Webster, M.M., Ward, A.J., 2011. Personality and social context. Biol. Rev. 86, 759-773.

Webster, M.M., Ward, A.J.W., Hart, P.J.B., 2007. Boldness is influenced by social context in threespine sticklebacks (Gasterosteus aculeatus). Behaviour 144, 351-371

Wilson, C.D., Arnott, G., Elwood, R.W., 2012. Freshwater pearl mussels show plasticity of responses to different predation risks but also show consistent individual differences in responsiveness. Behav. Process. 89(3), 299-303.

Wolf, M., Van Doorn, G.S., Weissing, F.J., 2008. Evolutionary emergence of responsive and unresponsive personalities. Proc. Natl. Acad. Sci. USA 105, 15825-15830.

Wolf, M., Weissing, F.J., 2012. Animal personalities: consequences for ecology and evolution. Trends Ecol. Evol. 27, 452-461

2

3

4

5

6

77


485

486

487

488

489

490

491

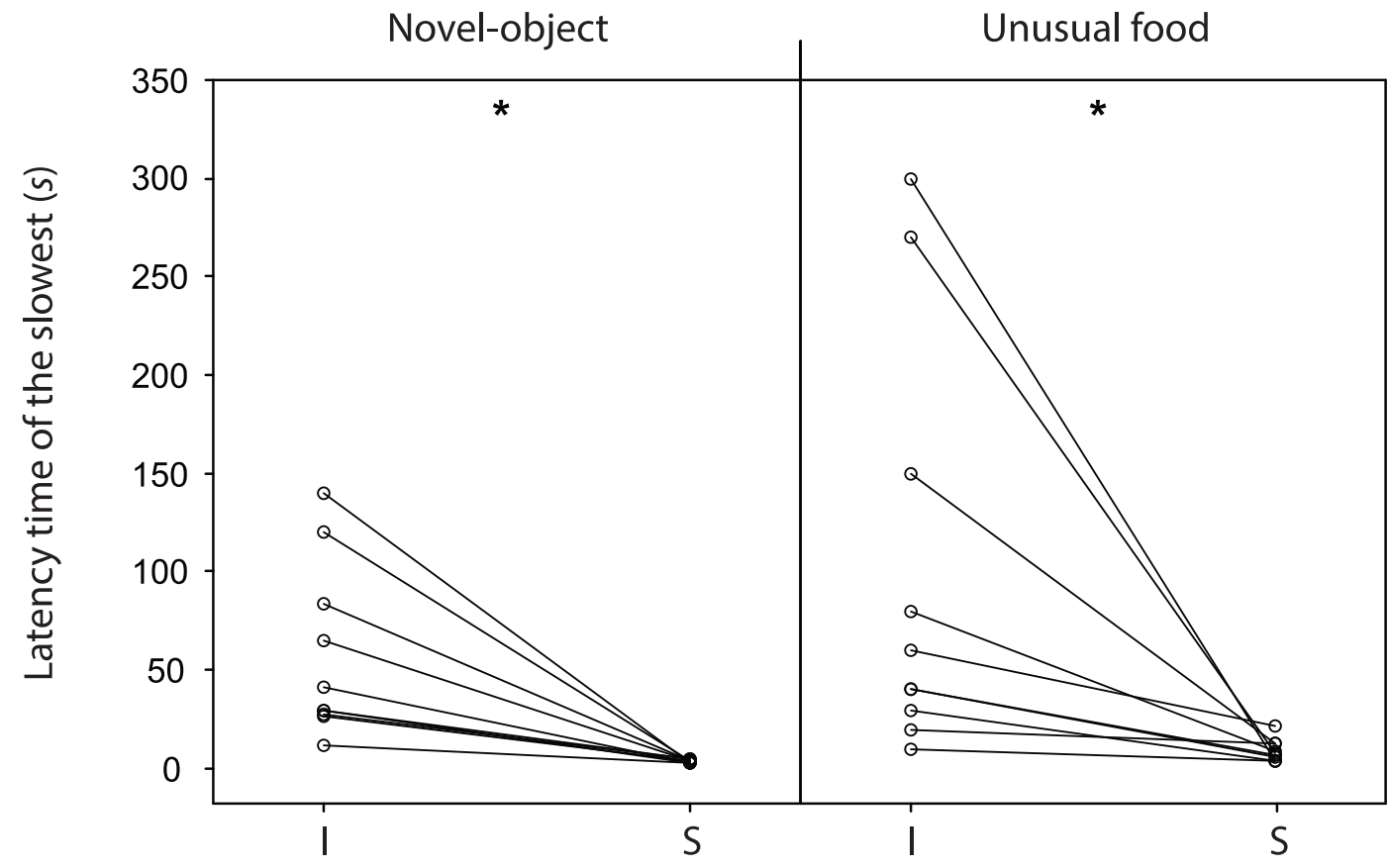

492

493

Figure 1: Differences in latency time between social conditions. The slowest solitary

494 response from each set of five fish during the individual test (I) was significantly slower than

495 the response of the slowest fish during the shoaling test $(\mathrm{S})$ in both the novel-object

496 inspection and the feeding context. Lines indicate change between social conditions [* $497 \quad P<0.05]$.

498

499

500

501 